\title{
Algunas anotaciones sobre la abeja y la miel en el mundo antiguo
}

\author{
P. Fernández Uriel *
}

Desde los tiempos más remotos, la miel y su productora, la abeja, tuvieron una importancia extraordinaria en la vida del hombre. Desde su utilidad material llegó a alcanzar un significado mítico y religioso, por ello analizar el papel jugado por la abeja en la antigüedad, es, a mi parecer, adentrarse en un mundo tan atrayente como apasionante donde aún nos queda mucho por conocer.

Expongo aquí los primeros resultados de este trabajo con el que me adhiero al merecido homenaje dedicado al Dr. Ripoll Perelló, al lado de quien tengo el orgullo de trabajar en el Departamente de Prehistoria e Historia Antigua de la UNED y disfrutar de su calidad humana y profesional. Vayan por delante mi felicitación y gratitud.

Es indudable que la primera utilidad de la abeja, ya en la vida del hombre prehistórico fue proporcionarle alimento. Muy posiblemente la primera bebida creada por el hombre fue la "Hidromiel». Pero pronto pasó a inspirar una curiosidad y una admiración tal, que llegó a ser objeto de culto religioso (Gimbutas, M., 1972; 181 y ss).

Por ello trataré la abeja, (probablemente la abeja Apis, de la familia de los Apidios) y su elaboración principal, la miel, en las dos vertientes principales relacionadas con el hombre: como alimento e industria $y$, en segundo lugar, su aspecto religioso.

* Departamento de Prehistoria e Historia Antigua, UNED, Madrid. 


\section{LA INDUSTRIA DE LA APICULTURA}

No debió ser practicada en el Oriente Próximo, o, al menos, carecemos de pruebas que lo confirmen. Sólo raras veces los textos babilónicos aluden a la miel (LAL: sumerio, DîSPÙ: acadio-babilónico) y cuando hacen referencia a la misma, suelen referirse más bien, a miel fabricada con jarabe de dátiles, de hecho la documentación indica que la apicultura no se introdujo en el Oriente Fértil hasta una época muy avanzada (Sonden, W. Von, 1987; 114) ${ }^{1}$.

Conocieron la miel de abeja los antiguos egipcios, que utilizaron para endulzar sus bebidas y alimentos, aunque es posible que el endulzante más habitual fuera la pepita del algarrobo, cuya vaina representa en su escritura el signo "Nodjem", que significa dulce (Montet, P., 1983, 72). En un principio los egipcios recolectaban la miel y la cera silvestre, que iban a buscar a lugares lejanos. Este debió ser un oficio muy antiguo, que gozaba de la protección real: los cazadores de miel, junto con los recolectores de resina de teberinto eran protegidos por los arqueros del faraón cuando marchaban en busca de estos productos a los "Uadis", lejos del valle del Nilo ${ }^{2}$.

En un momento que desconocemos, la abeja fue domesticada y se criaba en huertos y jardines, donde tinajas de alfarería se habilitaban para colmenas domésticas y la miel se guardaba en grandes cuencos de piedra sellados (Steindorff und Wolf. 1932, 18).

Es más probable que el cultivo de la abeja existiera en Asia Menor, aunque los datos que poseemos para su estudio son a todas luces escasos e inciertos.

\footnotetext{
1 Referencias a la miel se encuentran en los mitos sumerios y acadios. Valgan como ejemplo de estos: Mitos de Dumuzi y Enkimdu, pág. 107: “Si el me diera su buen pan, yo le daría a él mi queso con miel a cambio"; y en el Mito de La Hierogamia Cósmica, pág, 56,: "La tierra alegremente, originó la abundancia, exudó el vino y la miel...;" “...amontonó las uvas y la miel en los almacenes ...". Según Mitos Sumerios y Acadios. Edición preparada por $\mathrm{F}$. Lara Peinado. 1984.

Según W. von Sonden en el Creciente Fértil no se practicó la apicultura hasta una época muy avanzada. Así el gobernador Shamāsh Resŭ-Ussur se vanagloriaba de introducir la abeja en el Eúfrates Medio. Ver también Ebeling, R.L.A. II, 1983. Columna 25. Agradezco desde aquí la preciada ayuda del Dr. F. Lara Peinado en el estudio de este apartado.

${ }^{2}$ Papiro Harris, I, 20 b-12-21 a; I, 65 C, 7-8.
} 
Así, podríamos comprobar que la abeja fue conocida por los hititas y gozó de tal admiración, que la consideraron digna de aparecer en su mítología como servidora de sus dioses (Bernabé, A., 1979; 50, 55 y 58; mito de Telepinu) y las escasas referencias que se encuentran a sus productos, la miel y la cera, demuestran que eran consideradas como substancias muy preciadas, la primera como alimento exquisito (Mito de Hedammu, pág. 162: "Como miel se los va tragando..."), digno de ser ofrecido a los dioses (Plegaria de Muwatalli al dios de la tempestad de Pihassa, al que ofrece panecillos rellenos de miel y aceite fino, pág. 285) y la segunda, como elemento de purificación: (Mito de Telepinu, pág. 58: «Ponlo en pie, toma cera, límpiale los ojos y las manos, purifícalo y tráelo ante mì).

Sin embargo, desconocemos la existencia de la apicultura en el mundo hitita. Cabria la posibilidad que se utilizase la miel silvestre, sin menoscabar por ello la admiración y curiosidad hacia la abeja, que mereció un puesto en su mitología.

Cuando la Biblia alude a las abejas, califica a la misma como un maravilloso y admirable insecto por su comportamiento social ${ }^{3}$, y como artífice la miel y la cera, importante fuente natural de riqueza ${ }^{4}$. La miel, en las Sagradas Escrituras, es citado como un preciado alimento, nutritivo y de excelente sabor ${ }^{5}$.

Sin embargo, las alusiones referidas a la abeja y a la miel, parecen indicar que la primera se encontraba en estado silvestre y que el hombre obtenía su preciado producto recolectándolo.

La industria de la apicultura se encuentra documentada en la Antigüedad Clásica, donde ya era calificada como fructuosa y rentable. No hay que olvidar que en la alimentación, su principal uso correspondería al azúcar de nuestro tiempo. Por ello fue empleada principalmente en confiteria ${ }^{6}$ :

\footnotetext{
${ }^{3}$ Deuteronomio, I, 44.

${ }^{4}$ Exodo, 3, 89; “He bajado para librarle de las manos de los egipcios y subirle a esta tierra que mana leche y miel».

5 Jueces, 14,8; I Samuel, 14, 26-28; II Samuel, 17, 28-29; Jeremias 41,8.

${ }^{6}$ Escritores de la Antigüedad han dedicado parte de su obra al tema de la abeja y de la apicultura: VIRGILIo consagra a la cría de la abeja el canto IV de sus Georgicas. Otros poetas alaban la abeja y la pureza de su miel, como ARIStoteles: De animi. Plinio en sus Naturales Historiae describe sus conocimientos técnicos sobre la apicultura. VARRÓN en De Re Rustica III; escribe sus experiencia sobre este tema.

Otros autores también nos hablan de la industria de la apicultura: Columela, Cornelio, Celso e Higinio. Dion Casio nos traduce en griego la obra de Magón, el cartaginés, Meré-
} 


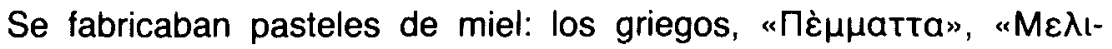

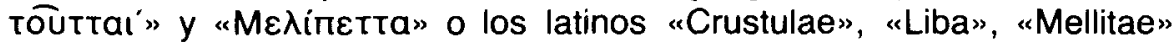
y “Placentae», utilizados al final de los festines romanos, o las frutas confitadas con miel que nos habla Columela, incluso solamente la miel, era considerada como un excelente postre. (Renard, W., 1961, 19; Blümer, H., 1920, 334) ${ }^{7}$. Con miel se preparaban bebidas dulces. Además de "Hidromiel»", las llamadas "Aqua Mulsa Invetera» ${ }^{9}$, "Mulsum» ${ }^{10}$,

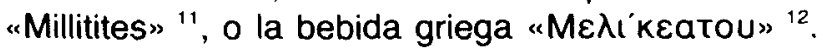

En farmacología, se tenía tal confianza en la medicación hecha con miel, que se atribuía al Sol el mérito de haberla inventado ${ }^{13}$.

Se utiliza sóla o mezclada con otras sustancias medicinales, sirviendo para curar heridas, envenenamientos 0 afecciones del pecho, la nariz, los ojos y las orejas (Gil, L., 1969, 99).

Fueron importantes las bebidas medicinales hechas con miel: « $\Theta a-$

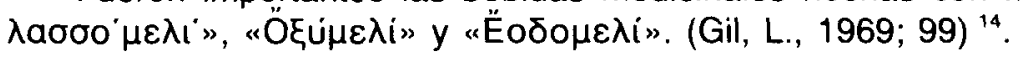

Se utilizaba la miel igualmente en perfumería, mezclándola con aceites aromáticos "Ungüenta» ${ }^{15}$.

Los joyeros empleaban la miel para la limpieza de ciertas piedras Ilamadas "Colchlides", que, tras ser puestas con miel, generalmente miel de Córcega, poco comestible, se las sometía luego a la acción del fuego durante siete dias y siete noches ${ }^{16}$.

Plutarco menciona que los tejidos de púrpura resistian de una manera asombrosa el paso del tiempo, si habian sido tratados con una

crates de Efeso también dedicó sus estudios a la abeja.

De otros autores apenas nos han llegado algo de su obra como Fístico de Taso, Neptolemo o el poeta Nicandro que realizó una "MENoovi Yi'ka" en honor de las abejas, que no se ha conservado, pero que es un testimonio claro de la admitación que este insecto causaba en la Antigüedad y que Petronio calificó de divino: "Apes...ego divinas bestias puto" (Styr., 56).

${ }^{7}$ PLIN., Nat. Hist., XXXIV, 14-15 y XXXV, 15; Suet. Neron, XXVII; Colum, XII, 47; PETR. Satyr., XXXV, 1-5.

${ }^{8}$ PLUt., Qv. Sympos., IV, 6, 2; PLIN. Nat. Hist., XXXI, 69.

${ }^{9}$ Colum., IX, 13; PLIN., Nat. Hist., XXXI, 69.

10 Petron.. Satyr., 114, 24; Marcial, Epigr., XIII, 108.

"PLIN., Nat. Hist., XIV, 85 y XXII, 108.

12 Homero, Odisea, X, 520; Oed. Col., 482.

13 PLIN. Nat. Hist., VII, 197.

14 ArISt. Etic Nicom., V, 9-15; MIR. Ausc, 18; PLIN. Nat. Hist., XI, 37 y XII, 107.

15 PLIN. Nat. Hist, XIII, 18.

${ }^{16}$ Todavía se utiliza la miel para el tratamiento de ciertas piedras preciosas como el ágata. Ver Daremberg-Saglio. Dic. Ant. Clasic., III, 2, 1700; Plin. Nat. Hist., XXX, 47. 
técnica especial, utilizando la miel. Aunque desconocemos con exactitud en qué consistía este procedimiento ${ }^{17}$.

Como vino cocido y salmuera, la miel tenía un uso doméstico para conservar las olivas negras, producto siempre apreciado en los países meridionales ${ }^{18}$.

Toda esta utilización de la miel en la Antigüedad Clásica, exigiría una gran demanda de la misma por parte de la sociedad, que originaría un comercio y una difusión de este producto en el mercado.

Aunque se encuentran algunos datos proporcionados por las fuentes arqueológicas y literarias, el comercio de la miel, su difusión y transporte no está debidamente estudiados y sólo existen pequeños análisis de carácter local y esporádico.

Quizá fuera en Grecia donde la industria de la apicultura estaba más desarrollada, siendo la miel del Ática la más apreciada de todas. Atenas era gran productora de miel ya en tiempos de Solón ${ }^{19}$.

Sólo se atrevía a rivalizar con la miel del Ática, la producida en la isla Caymna ${ }^{20}$.

En Tesalia, Acaya y Arcadia se practicó así mismo la apicultura. También era importante en Eubea, Argos y en las Cícladas, principalmente en Scyros ${ }^{21}$. Chipre y el Norte de Africa, igualmente, fueron productoras y exportadoras de miel ${ }^{22}$.

Durante la República romana, Italia fue deficitaria de miel, debiendo ésta de ser importada de otras provincias, principalmente de Sicilia y de Hiblea.

A comienzos del Imperio, se empieza a dar cierto empuje a la apicultura en la Península Itálica, destacándose como centros productores,

17 Plutarco, Alex, XXXVI.

${ }_{18}$ Citado por Daremberg-Saglio. Ibidem. 1710.

19 Aristóteles comentaba la gran producción de las colmenas del monte Himeto: ARISt. Anim. His. IX, 40, 24; Plutarco, Solón, 23; Han alabado la miel del Ática: LuClano, (Nav. 23); Plinio: (Nat. Hist., XXIII, 82) VIRGILIO, (Georg., IV, 178); Ovidio, (Ars. Anim. III, 1687); Estrabon, (IX,23), Pausanias, (I, 32) y Valerio flaco, $(I, 394)$, entre los más importantes autores de la Antigüedad.

${ }^{20}$ Estrabón, X, 5; Plin., Nat. Hist., XI, 32.

${ }^{21}$ COLUM., IX, 14-19; PLIN., Nat. Hist., XI, 59.

${ }^{22}$ VIRGil., Georgicas, IV, 287-294. 
Tarento $^{23}$, en los Apeninos ${ }^{24}$, en el valle del Po, en Mantua, Hostillia y Ferrara $^{25}$.

Pero la miel más apreciada por los romanos fue siempre la miel del Ática, como lo demuestran numerosos testimonios literarios ${ }^{26}$.

En cuanto a las provincias de Germanía, se producia miel en los Alpes, destacándose ésta por su grosor extraordinario ${ }^{27}$.

Y sobre Hispania comento Plinio:

«In Hispania mules provehunt simile de causa. Tantumque pabulum refert ut mella quoque venenate fiant" ${ }^{28}$.

Procedente de Hispania es conocida la inscripción grabada en una tablilla de plomo con un nombre: «C. Valerius Capito", que ha tomado posesión de un terreno para el cultivo de la miel: "Alvari locum occupavit" (C.I.L., II, 2242).

Las mieles de buena calidad resultaban insuficientes ante la gran demanda de las mismas que la sociedad exigía. Ello provocó que fueran adulteradas, adiccionando a las mismas materias poco costosas, o mezclándolas con otras mieles de peor calidad, según nos refiere Plinio ${ }^{29}$.

Debido, pues, a esta gran demanda de miel, lugares poco propicios para la agricultura o la ganadería, encontraron su fuente de riqueza en la cría de la abeja, como Córcega, ya gran productora de miel y de cera en tiempos de los etruscos ${ }^{30}$.

Autores como Varrón, Virgilio y Cicerón alababan las ventajas de las fincas rústicas no aptas para la vid o el ganado y dedicadas a la apicultura. Con un campo cuidado, se podría llegar a tener una buena producción de miel y de cera, que luego se utilizaría para la exportación, como el ejemplo de los dos hermanos de Faleria, que llegaban a vender miel con una ga-

${ }^{23}$ Horacio, Carm., II, 6, 13; Macrob., II, 12; Estrabon, VI, 6; Virgillo, Georgicas, IV, 139; PLIN. Nat. Hist., XI, 33.

${ }^{24}$ PLIN. Nat. Hist., XI, 33.

${ }^{25}$ VIRGILIO, ECl., I, 54; PLIN. Nat. Hist., XXI, 73.

${ }^{26}$ VarRón, III, 16, 14; ECl., 55; Ovidio, Ars. Anim., II, 517 y III, 150; Tristia, V. 13, 16, 22 y 38; Estrabón, VI, 22; Plin. Nat. Hist., XI, 32; Silio Italico, XiV, 97; Marcial, Epigr., X, 43, V, 39 y XIII, 104

${ }^{27}$ Plin. Hat. Hist., XI, 33; Estrabón, IV, 5.

${ }^{28}$ PLIN. Nat. Hist., XXI, 73-74.

${ }^{29}$ PLIN. Nat. Hist., XI, 36.

${ }^{30}$ Diodoro, V, 13. 
nancia de más de 100.000 sestercios al año, o el conocido viejo senador de Tarento, enriquecido gracias a la industria de la miel ${ }^{31}$.

Muy frecuentemente, los tarros de miel de uso doméstico, estaban bellamente decorados, incluso, algunos de ellos muestran una gran calidad artística, como el tarro de miel, depositado en el Museo Británico, cuya decoración, referida al mito de Glauco, se atribuye al pintor Sotades (Burn, L., 1985, 93-105).

En Roma, se utilizaban para guardar y transportar la miel, pequeñas ánforas de paredes casi cilíndricas y de base afilada, de boca ancha, pero fáciles de tapar, llamadas "Lagena" y "Cadus", vasijas muy semejantes en su tipología a las utilizadas para guardar frutos secos y pescado salado. Son breves los datos de tipo arqueológico recogidos sobre el transporte y la importación de la miel. Destaquemos los fragmentos de cerámica con inscripción de Pompeya y Vindonisa recogidos por Callender (Callender, M. H., 1965, 40).

Estas vasijas utilizadas para guardar la miel, son citadas con alguna frecuencia por los autores literarios. Citaré como ejemplo el famoso y bello epigrama de Marcial: "¿No se es feliz tirando del pez que salta colgado del tembloroso sedal y escurriendo la rubia miel del rojo "Cadus" de barro?" ${ }^{32}$.

\section{LA ABEJA Y LA MIEL EN SU ASPECTO RELIGIOSO}

El carácter sagrado de la abeja se remonta a un origen prehistórico: La abeja pasaba por ser la representación femenina de la potencia de la naturaleza en el ámbito del Mediterráneo Oriental (M. Gimbutas, Ibídem; J. J. Bachofen, 1987, 95).

Prueba de ello, en Asia Menor y Anatolia, la abeja, considerada como un ser admirable, fue elegida por la diosa HannaHanna, la madre de los dioses hititas, para buscar a Telepinu, purificarle y lograr que con su vuelta, la naturaleza recuperara la fertilidad perdida. La abeja llevó

\footnotetext{
31 Varrón, Ili, 16-17; Virgilio, Georgicas, IV, 114-118; Cicerón, De Senec, 5, 6.

${ }^{32}$ Marcial, Epigr., I,55.
} 


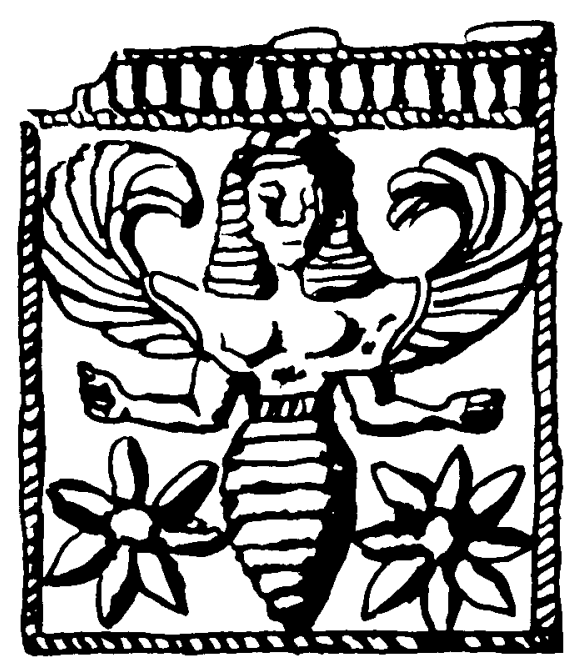

Fig. 1. Placa encontrada en la Necrópolis de Camiros, con la representación de una posible "Diosa-abeja", relacionada con Artemisa, según Salzmann.

con éxito su misión y fue digna de ocupar una posición cerca de las divinidades ${ }^{33}$.

Pero es en Creta donde las abejas alcanzan una estimación tal que sus representaciones de carácter ornamental tienen una extraordinaria belleza artística (recordemos la famosa joya en oro hallada en la Necrópolis de Krissolakkos de Mallia), al mismo tiempo que adquieren un valor celeste y su condición y facultades están intimamente ligados a los dioses: Zeus, Dioniso, Aristeo, Deméter, Artemis, Perséfone o las Ninfas (fig. 5).

Es en Creta donde las abejas alimentaron con su miel y protegieron

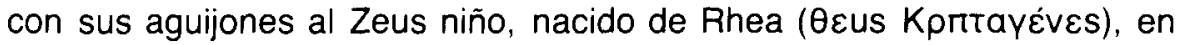
una cueva sagrada del monte Ida. Por ello, estas abejas tomaron el

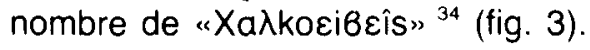

33 Cfr. pág. 2.

${ }^{34}$ Para Eufronio, las abejas aparecieron por primera vez en el monte Himeto, en el Ática, en tiempos de Erecteo, "( $\mu \eta \tau \tau \tau$ tós"=dulce como la miel). Para Eumero, surgen en Ceos y para Euctenio, en Nemea. Ver Euctronio, Metamort. Nicand. Alex., 450. También $P$. Wissowa, Real. Enc. XU,1-363. Sobre el nacimiento y la infancia de Zeus: Diod., Bibl., $\checkmark, 70$. Ello está relacionado con la leyenda de Céleo, Layo y sus compañeros convertidos en pájaros como castigo por tratar de robar la miel de la gruta sagrada en el monte Ida, donde Rhea dió a luz a Zeus. Ver P. Grimal. 1965. 95. Este mito está representado en el anfora Vulci. Cat.of Was.Brtt. Mus., vol. II, pag. 122 y B., 177. 


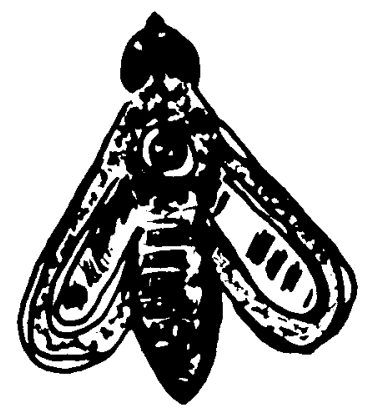

Fig. 2. Joya realizada en oro con trabajo de granulado. Fue adquirida por el Museo Británico, donde se encuentra depositada en la actualidad. Se desconocen las circunstancias de su descubrimiento, pero es muy posible que sea originaria de Creta.

Esta leyenda del nacimiento de Zeus relacionado con las abejas nos lleva al mito de Meliseo, rey de Creta y el primero que, según la tradición, introdujo el sacrificio a los dioses y las procesiones religiosas. Su hija, Melisa, fue nodriza del niño Zeus, alimentándole con leche de cabra y miel. Fue la primera sacerdotisa de Rhea ${ }^{35}$.

Otra huella del antiguo culto a las abejas de origen cretense, o al

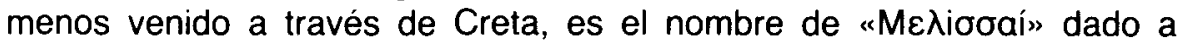
las sacerdotisas de Apolo, quizá derivado de Melisa, hija del rey Meliseo.

Zeus tuvo con la ninfa Othrys un hijo, que por ser criado con miel, se llamó Meliteo y fundó la ciudad de Melite ${ }^{36}$.

Diónisos, igualmente, fue criado con miel de niño, una vez resucitado por Rhea, por las Ninfas o bien por Macris, hija de Aristeo ${ }^{37}$.

Aristeo, hijo de la ninfa Cirene, fue adiestrado por las Ninfas en las artes de la lechería y la apicultura, asi como en el cultivo de la vid, que a su vez, transmitió a los hombres. Por ello pasaba por ser quien introdujo la cría de las abejas en Arcadia y los conocimientos de la apicultura que se extendieron en el mundo griego.

${ }_{35}$ ApOD. Bibll., I, 1, 6; LACT. Ins. Div. I, 22; HIG. Astr. Poet., II, 13 DIOD. Sic., XVII, 7, 2; Nonnos, Dionis., XIII, 145; VIRGILIo. Georgicas, IV, 152; Colum., De Re. Rust., IX, 2.

36 ANT. LiB. Trnasph., 13.

"Apoll. Rod., Arg., IV, 129, 34; Ovidio, Phast., III, 735. 
Castigado por los dioses por la muerte de Eurídice, esposa de Orfeo, fue enviada una epidemia que acabó con sus abejas. Ayudado por su madre y por los consejos de Proteo, logró obtener nuevos enjambres ${ }^{38}$.

Lymo, hijo de Apolo y Euadne fue alimentado con miel por dos serpientes. Fue adivino y famoso sacerdote, ascendiente de la familia de los Yámidas, en Olimpia ${ }^{39}$.

La miel era considerada como alimento apropiado para las divinidades, por dos razones fundamentales:

- Por la naturaleza de la misma: Se la consideraba incorrupta desde su formación. Era el producto más puro de la naturaleza orgánica, aquél en que aparecen estrechamente unidas la producción animal y vegetal.

- Por ser un alimento principalísimo. Los niños en la antigüedad se alimentaron fundamentalmente de leche y miel ${ }^{40}$. Tales eran sus propiedades nutritivas e higiénicas.

Si la miel se consideró digna de la alimentación de los dioses tenía propiedades mágicas para los hombres. A las abejas se les atribuía la inteligencia y un profético talento. Quien tomaba su miel, asimilaba sus propiedades. Asi, quienes eran poseedores de dones considerados como sobrenaturales: Aedos, sabios y profetas, se decía que habian sido alimentados con miel en su infancia ${ }^{41}$.

La connotación religiosa de la abeja, que, como se dijo anteriormente, bien puede remontarse a épocas prehistóricas, derivaba de que ésta significó para los antiguos un ejemplo de sociedad, como ya expresó Virgilio.

También Aristóteles coloca a las abejas por encima de los hombres de los tiempos primitivos porque la Gran Ley Natural alcanzaba en ellas una expresión más perfecta y sólida que entre los humanos, idea que recoge Virgilio en sus Geórgicas.

38 Pausan., VIII, 2, 4, y X, 17, 3; Nonnos-Dion. V, 229; Virgillo. Georgicas, IV, 317; Cic. De Div., I, 57; Apol. Rod. Arg., II, 500.

${ }^{39}$ PIND. Olimp., VI, 45.

40 PInD. Olimp., Vi, 36, 47: «In Graecia infantes primum mella alebantur quod ex Paulo et Aetio monstrat is vossus ad Barnabae». Epist. pág. 311.

${ }^{41}$ Pausanias, IX, XL-1. El oráculo de Trofonio fue conocido por los beocios gracias a un enjambre de abejas. El consultante de este oráculo penetraba en el santuario con un pastel de miel en cada mano para calmar a los dioses infernales. Menandro, IX. 187. Ver M. BuIsson, 1976, 54 . 


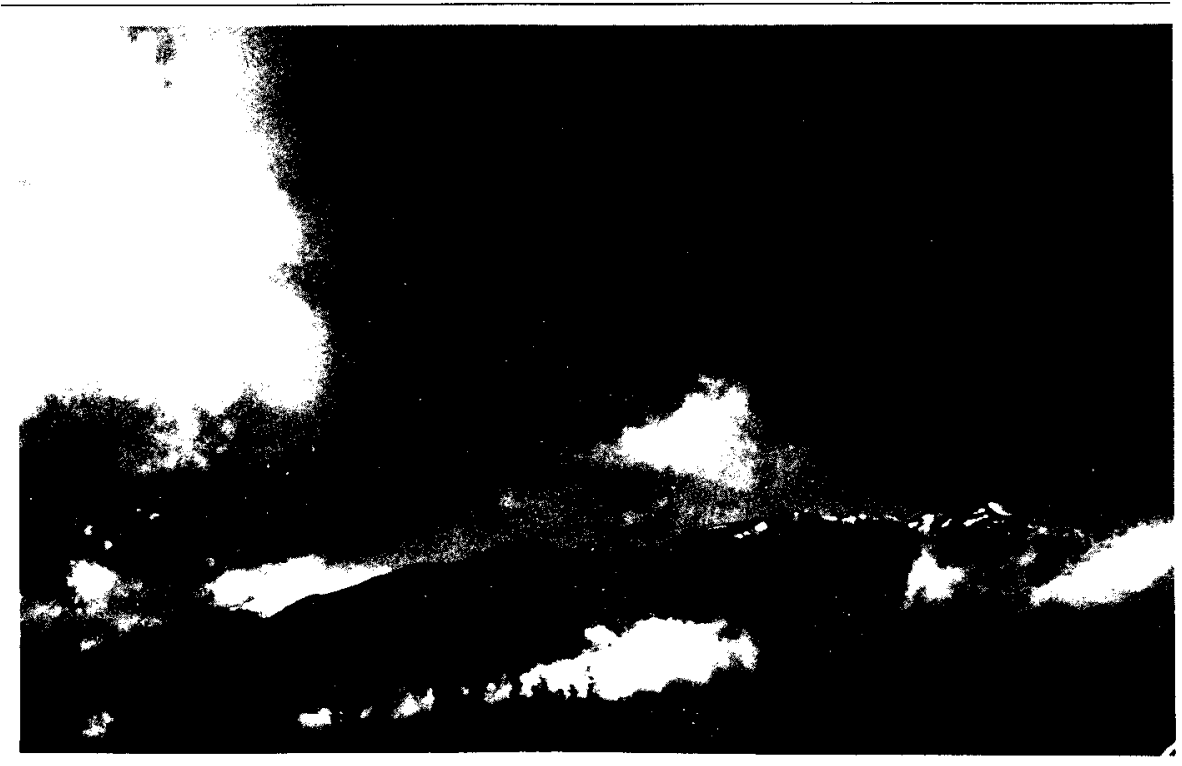

Fig. 3. Vista de la cumbre del Monte Ida, en Creta, según la Mitologia, Zeus fue alli depositado por Rhea para que fuese alimentado y protegido por las abejas $y$ donde transcurrió la infancia del dios.

Pero sobre todo, fue la forma de vida de la abeja, que mostraba la ginecocracia en sus formas más clara y pura: "Solae communis gnatos consortiae tecta urbis habent, magnisque agitant sub legibus aevum: et patriam solae et certos novere penatis" ${ }^{42}$. Por lo que se la relacionaba, fundamentalmente, con las divinidades de tipo femenino: Artemis, Deméter y Perséfone ${ }^{43}$.

La primera por su actividad incesante, habilidad y destreza.

La segunda por su representación de la maternidad y la fertilidad.

La tercera por sus connotaciones de carácter ctónico.

Y con todas ellas, por su significado de perfección y de pureza.

\section{Artemis}

Aunque las referencias son vagas y escasas, se podría, al menos, conjeturar la posibilidad de una diosa abeja de tradición prehistórica en

42 VIRGILIO, Georgicas, IV, 153.

43 Aristoteles, Ateneo, VIII, 1353; VIRgilio, Georgicas, IV, 154 


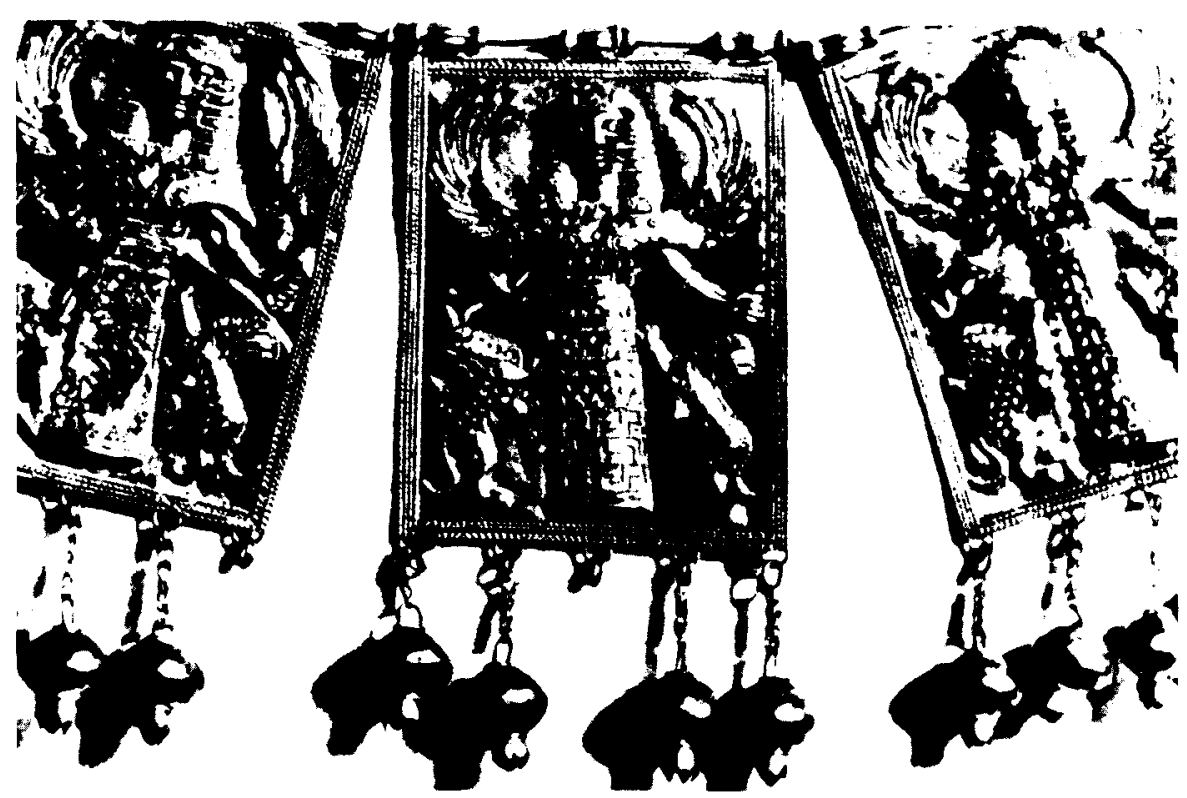

Fig. 4. Detalle de las placas del llamado "Cinturón de Rodas".

Anatolia y Asia Menor, asimilada por la cultura hitita y que se extendiera en el mundo egeo, llegando a un sincretismo con la diosa Artemisa.

Es en Éfeso donde la abeja se encuentra asociada de una manera más clara y latente con la diosa.

Si se considera Éfeso como la antigua ciudad litoral del reino hitita de Arzawa, mencionada en las tablillas cuneiformes con el nombre de Aspasas, datada ya en el II milenio a.C. (El relieve de Karabel, al sur de Sardes sería un preciado testimonio de la presencia hitita en la Anatolia septentrional), especificaríamos que en la palabra Aspasas se encuentra el vocablo "apis", que en indoeuropeo prelatino significa abeja. Así, la palabra "appi» ya se encuentra en antiguos dialectos luvitas como el istanuvio, equivalente a "pi» del palaita (Sanz Mingote, L. 1988, 76) ${ }^{44}$.

44 Los textos del luvita, según las últimas investigaciones, dejan descubrir un cuarto dialecto, el istanuvio, que, a pesar de que no se conocen más que algunas frases, tiene rasgos peculiares. En el mismo aparece claramente la particula «appi»=abeja. 
Por ello autores como Önen se preguntan si la antigua ciudad de Apasas sería el lugar de culto de la diosa abeja, cuya tradición religiosa recogería Éfeso (Önen, U., 1985, 2).

Las monedas más antiguas de Éfeso, (datadas en torno al siglo $\mathrm{V}$ a.C.) aportaban la abeja como símbolo tradicional de la ciudad (Himer, M., 1964, 131; Hill, G. T., 1966, 1).

La abeja, además, era el símbolo de la dulzura, el dolor y la fecundidad que jugaban un papel tan destacado y preponderante en la Artemis Efesia.

La representación de la diosa, tan diferente de las divinidades femeninas helénicas, (torso con gran profusión de senos por lo que recibía el epíteto de "по pedestal cilíndrico, todo ornado en compartimentos donde se representaban animales simbólicos: toro alados, grifos, carneros y abejas que hacian de Artemisa Efesia una diosa protectora de la Naturaleza en sus fuerzas vitales, en su fecundidad y en sus ciclos de la vida, donde encaja claramente el símbolo de la abeja ${ }^{45}$ (fig. 6).

La representación de la abeja relacionada con el culto de Artemisa, se encuentra en distintos puntos del Mediterráneo:

Hay monedas en Quersoneso y Tracia con la efigie de Artemisa en el anverso y la representación de la abeja en el reverso. También se encuentra el símbolo de la abeja en monedas de Esmirna, Erytrea, Arados y Parium (Hill, G. T., 1966, 167).

Es más significativa aún, en la relación de la diosa Artemisa con la abeja, los relieves de las placas encontradas en la Necrópolis de Camiros, en Rodas, publicadas por Salzmann (fig. 1).

Representa una figura femenina alada, que desde la cintura tiene el cuerpo abdominal de abeja.

Salzmann relaciona esta figura con Artemisa, al encontrarle paralelo con la llamada "Artemisa Pérsica", hembra alada que tiene un león a cada lado, estudiada por Roscher y recogido por A. B. Cook (Cook, A. B., 1895, 12).

${ }^{45}$ A la representación de la Artemisa Efesia, hay que añadir los elementos orgiásticos y totalmente orientales que se encuentran en su culto, tan diferente de la religiosidad griega. Ello hace pensar en influencias e incluso, sincretismo con otra divinidad de origen asiático (¿Artemisa Pérsica?). 
Para Cook todo ello ofrece el poder conjeturar la posibilidad de existencia de una diosa abeja, quizá identificada con una Artemisa-abeja.

De hecho la llamada "Artemisa Lunar" era representada muy a menudo alada. Sus alas simbolizaban el curso del astro a través de la

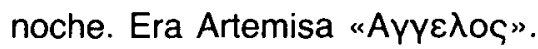

La antigua teoría de Persson, (Persson, A. W., 1941, 9), favorece la identificación de la Artemisa-abeja alada, al considerar que la «Artemisa Lunar" se relacionaba con la abeja, siguiendo la antiquísima creencia de que la miel provenía de la luna, en la que la esfera terrestre era el panal y las estrellas, las abejas.

Pausanias cuenta que sobre el cofre de Cipselo, Artemisa tenía alas: "Artemis tiene, no sé por qué, alas en las espaldas, y lleva en el brazo derecho una pantera y en el otro un león" ${ }^{46}$.

La escultura arcaica encontrada en Delos, atribuida a los escultores chiotas Mikkiades y Archemos, vestida con túnica y diadema, está dotada de alas en su espalda y talones y fue identificada por Homolle como una Artemisa alada (Homolle, M. 1879, 393). Sin embargo, otros autores creen que se trata de una representación de Nike.

Ello nos lleva a relacionar, en alguna medida y con la prudencia exigida, ciertas representaciones de divinidades femeninas aladas con la posible "Artemisa-abeja», como las representadas en las placas de cinturón de Rodas (fig. 4).

Divinidades femeninas aladas han aparecido también en el levante hispano y más concretamente en llici (Elche).

Las cinco figuras femeninas aladas que aparecen pintadas en las cerámicas ilicitanas son representaciones de la diosa púnica Tanit, pero cabe pensar, según J. M. Blázquez, que esta divinidad se identificara con una diosa indígena que ya anteriormente sufriera un sincretismo con Artemisa Efesia, de hecho, esta diosa fue fácilmente asimilada por los iberos que conocieron su culto a través de los colonos griegos (Blázquez, J. M., $1975,35-39)^{47}$.

46 Pausanias, Descrp. Graec., V, XIX, 5.

${ }^{47}$ Estrabon, IV, 1, 5. La diosa contaba en la peninsula ibérica con cuatro santuarios situados en: Ampurias (Estrabón, III, 4, 8), Sagunto (Plinio, Nat. Hist., XVI, 216, recogido por A. García y Belliđo, MM, 4, 1963, 87 y ss.), Hemeroscopeión, (Estrabón, III, 4, 6) y Rosas. Estrabón refiere que en la Península Ibérica se celebraba el culto a la diosa con el mismo ritual que en la metrópoli. 


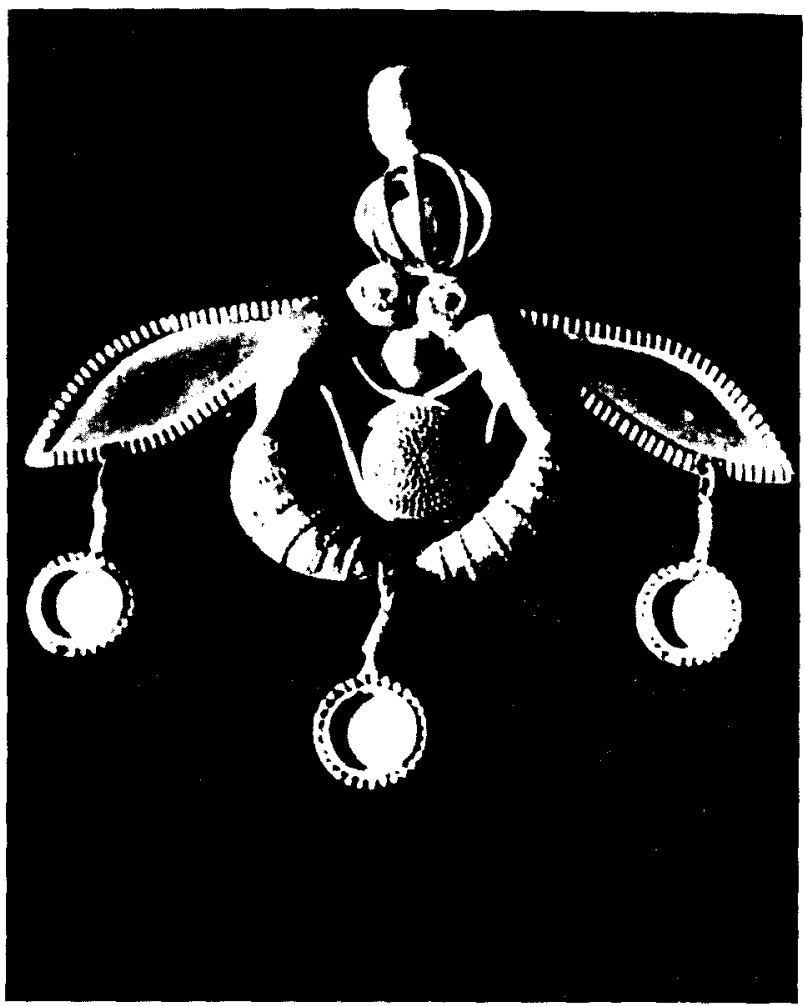

Fig. 5. Joya realizada en oro que representa dos abejas afrontadas libando el polen. Hallada en la necrópolis de Krissolakkos, Mallia (Creta).

El culto de Artemisa estaba igualmente relacionado con la miel, producto de la abeja:

Pausanias, en su narración sobre el templo de Artemisa Hyminia, cerca de Orcómenos, cuenta que la sacerdotisa y el sacerdote de la diosa debian preservarse puros, no sólo sexualmente, sino también en otros aspectos, como en sus abluciones y su sustento, el cual debía ser a base de miel. Incluso no se les permitía entrar en la casa de un ciudadano privado.

Continua contando Pausanias que ciertos ciudadanos de Efeso y Orcómenos, durante todo un año festejaban en honor de Artemisa. Estos 


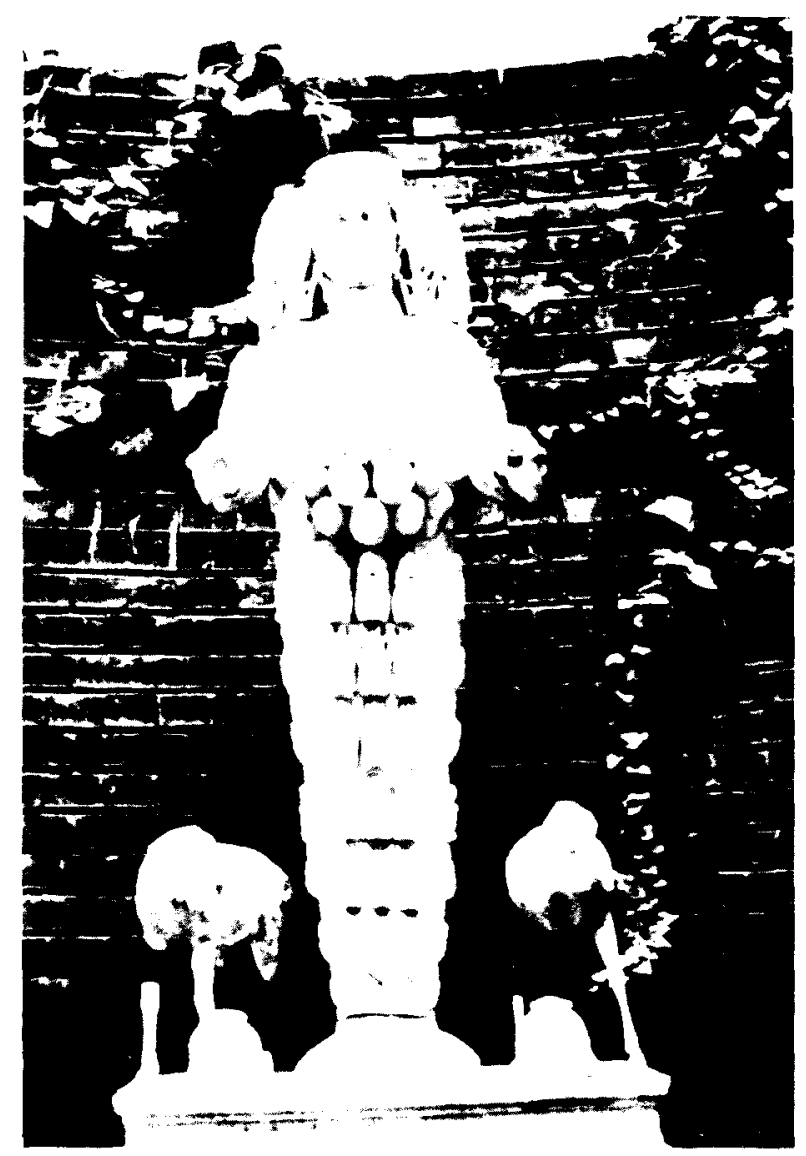

Fig. 6. Representación de la diosa Artemisa. Museo de Efeso (Turquia).

devotos, llamados "Ëoō̄ $\varepsilon \varepsilon \varsigma$ ", durante ese tiempo, se abstenían de carne animal y su dieta era a base de miel ${ }^{48}$.

De todo ello, se podría deducir la existencia de una primitiva diosaabeja de origen prehistórico, que, más adelante, llegaría a identificarse con una divinidad femenina alada de la fertilidad, probable germen de la Artemisa anatólica.

Pero carecemos de pruebas suficientes para afirmar la existencia de un culto a la diosa Artemisa-abeja, ni siquiera en Efeso ni en Rodas.

48 Pausanias, Descro. Graec. VIII, XIII, 1. 


\section{Deméter}

Deméter es el otro gran miembro femenino del Panteón asociado a la abeja, por su íntima conexión a la fecundidad cuyo símbolo es la abeja reina y porque la miel es el puro alimento materno. La miel y la leche pertenecen a la maternidad, siendo el vino, el principio dionisíaco masculino de la naturaleza.

Fue Deméter, según Euctronio, quien enseñó a las abejas a construir sus panales en los árboles huecos. Pero es Virgilio en la Eneida, quien cuenta la leyenda que envuelve a Deméter en una íntima conexión con las abejas ${ }^{49}$.

Una cierta dama llamada Melisa, llegó a conocer por la propia diosa los secretos de su ritual, advirtiéndole ésta que no los revelara. Las otras mujeres, furiosas de su negativa a contarlos la despedazaron. Deméter envió contra ellas y su vecindad una peste asoladora e hizo que un enjambre de abejas nacieran del cuerpo de Melisa.

Esta leyenda podría servir de inicio a que el término Melisas, ( $\mathrm{M \varepsilon}$ $\lambda\left(\sigma \sigma a i^{\prime}\right)$ ), fuese utilizado para nominar a las sacerdotisas del culto de Deméter y, quizá, por un abuso o extensión del lenguaje, fue siendo aplicado también a las mujeres que se iniciaban en los sagrados misterios de la diosa.

Las mujeres casadas participantes en los ritos de las fiestas « $\Theta \varepsilon \sigma-$

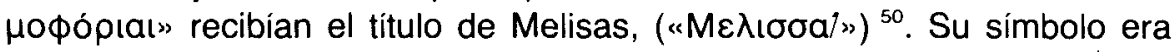
la abeja y tomaban de ella su significación de virtud, pureza, austeridad de costumbres, además de su adversión al desorden y al libertinaje (Detienne, 1983, 164) ${ }^{51}$.

Refuerza la conexión de los ritos de Deméter con la abeja, la narra-

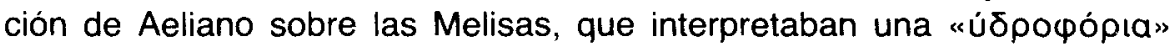
en honor de la abeja como objeto de culto y santidad. La misma interpretación aparece en Píndaro ${ }^{52}$.

La relación abeja-Deméter se extiende al culto de Perséfone sin que podamos especificar cuando.

${ }^{49}$ Euctronio, Metph. Nicand. Alex. 450, Virgilio, Eneida, I, 450.

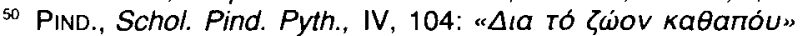

${ }^{51}$ Apol. de Atenas. FGR. H. 244. F. 89, CAlLim, Hymn. Apollo, 110, 111.

${ }_{52}$ Pind., Schl. Pin. Pyth., IV, 104. También Aelian, De Nat. An., V, 49. 


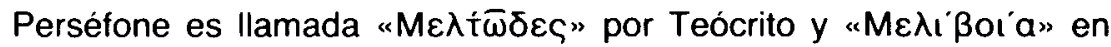
los versos de Lassos de Hemione recogidos por Ateneo ${ }^{53}$.

A. B. Cook recoge la opinión de $E$. Dübner, un antiguo comentarista

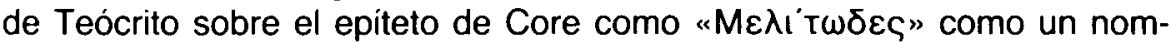
bre eufemístico para Perséfone debido al hecho de que las sacerdotisas de Deméter y Perséfone eran llamadas "Melisas" (Cook, A. B. 18897, 109). E. Neumann opina que la diosa abeja con sus atributos y caracteres (miel, panal) es un antiguo arquetipo cuya simbología fue aplicada a la divinidad: Artemis, Hécate y Deméter-Perséfone, que significaba el poder de la tierra, o, más bien, de la fecundidad de la tierra junto al poder de la vida y de la muerte (Neumann, E., 1970, 267).

De aqui que la abeja toma una nueva caracteristica en su simbolismo religioso como una criatura cthónica, reforzada por una conexión con Diónisos, alimentado por las Ninfas, o por Macris, con miel.

La miel y la abeja participaban en los misterios ctónicos de la vida y de la muerte de las divinidades Artemis-Hécate, Deméter-Perséfone y de Diónisos.

Apolodoro de Rodas hace a Jasón portador del sacrificio de la miel a Hécate, aunque para Cook, las connotaciones ctónicas de la abeja en el culto de Hécate no son las más ambiciosas (Cook, ibídem, 13) ${ }^{54}$.

Es posible que tenga mayor fuerza la abeja como símbolo de la

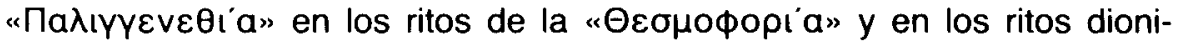
siacos.

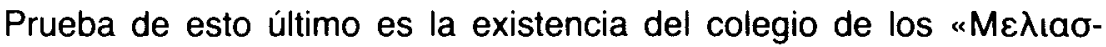
tai'», especie de cofradía báquica en el santuario de Diónisos en Melangeia (Mantinea, Arcadia) ${ }^{55}$.

La abeja misma por su origen mítico tiene una significación de vida y de resurrección, por tanto está intimamente ligada al ritual fúnebre:

- Por el mito de Glauco ahogado en miel y resucitado por el adivino Polyeidos ${ }^{56}$.

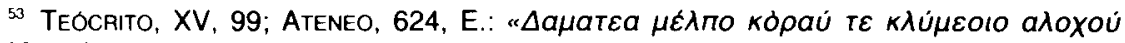

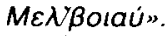

s4 Apollod. Rod. Arg., 111, 1035. Ver P. Wissowa, Real Enc., I, 68

${ }_{55}$ Pausanias, VIII, 6, 5. Según Pausanias los "MEגiautai" eran un colegio de bacantes, análogos a los dionisiacos. No ha especificado sus ceremonias, pero por el carácter

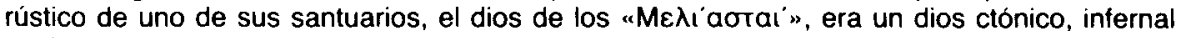
y silvestre.

st ApD., Bibl., III, 13; PInd. Schl. Pind. Pit., III, 96. Ver P. Grimal, 1966, 215. 
- En la leyenda de Aristeo, las abejas surgen de los novillos sacrificados ${ }^{57}$.

- En el mito de Melisa, sacerdotisa de Deméter, despedazada por no querer revelar sus misterios, de cuyo cuerpo surge un enjambre de abejas por designio de la diosa ${ }^{58}$.

Así como las abejas surgidas de una res, representaban la vida y la muerte del animal, y por lo tanto, creaban en torno a ella una resurrección, en el mito de Melisa, la abeja podria representar el alma de la sacerdotisa que tomaba forma de abeja. Las almas volvían a la vida como las abejas regresaban a la colmena ${ }^{59}$.

Representaciones de abejas han sido encontradas en tumbas, bien como motivo de decoración de las mismas, bien como objeto de ajuar funerario, en Crimea, Creta y Etruria principalmente (fig. 2 y 5).

La abeja en el Neoplatonismo y en el Orfismo está intimamente relacionada con el alma. Las escuelas místicas representaba a la abeja como un emblema de un alma que no había nacido todavía ${ }^{60}$.

Desconocemos si en la mente greco-romana la simbología de la abeja estaba relacionada con la inmortalidad o con la resurrección del alma. Es posible que, ante la mitología y las tendencias filosóficas, imaginara que la abeja fuera, en la liturgía fúnebre, más que un símbolo de inmortalidad, un signo de resurrección o de reencarnación.

${ }^{57}$ Este método supersticioso de reproducir las abejas se atribuía a Aristeo, la divinidad pastoral que enseñó a los hombres la agricultura: Dion CAsıo, Bibl., 81; APIANo, Cyneg., IV, 269. Nonnos, Dio. V, 232, Pindaro, Pyth., IX, 107). Él inventó la mezcla de vino y miel, (PLIN. Nat. Hist.. XIV, 16). Él guardó los enjambres de abejas ayudado por Las Musas en la llanura de Phitia, de las que aprendió la apicultura. Poseía el don de la profecía. La tradición relata que fue a Queos en obediencia a Apolo y alli permaneció haciendo sacrificios a Zeus Ikmaios para librar a las Cicladas de una peste.

Ha sido identificado con Zeus en estas islas con el nombre de Zeus Aristeios. En favor de esta identificación esta K. Brondel (Ver Daremberg - Saglio, Dicc. Ant., I, 1 pág. 424). También se identifica con Zeus Melisaios y con Zeus Melikios. El culto a Aristeo se encuentra extendido por Tesalia, Beocia, Eubea, Creta, Cerdeña y Sicilia.

58 Euctenio, Metamorph. Nicand. Alex., 450.

59 La idea es que la vida del toro se perpetúa en la vida de las abejas. Ello lleva connotaciones con el Toro divinidad, "Bouyevei ", recogido en Porfirio, (De Ant. Nymph., 180 y OviDIO, (Phasti, I, 379: "Fervent examine putri / De bove: "Mille animas una necata dedit"'".

60 En este sentido se relacionan las abejas con Las Ninfas, concretamente con las Ninfas del agua. Pensaban que las almas revoloteaban sobre el agua esperando su reencarnación. 
El protagonismo de la miel, tanto en el ritual funerario como en las ceremonias celebradas en honor de las divinidades ctónicas, es paralelo de su productora, la abeja.

En cuanto al primero, sabemos que en la antigua Grecia, se embalsamaba en miel los cadáveres de los niños y también los de grandes personajes que no se querían incinerar directamente, o a aquellos a los que se quería asegurar una duración eterna ${ }^{61}$.

El origen de esta práctica parece haber venido de Asia por medio de Creta. (Recordemos el mito de Glauco) ${ }^{62}$.

El tratar los cadáveres con cera y miel pudo tener un origen protohistórico. En la épica Homérica encontramos ejemplos de ello ${ }^{63}$.

Hay muestras de este ritual funerario en épocas posteriores. Quizá Alejandro es el personaje más famoso conservado en miel de estos soberanos ${ }^{64}$.

A los difuntos se les hacía ofrendas de vasos de miel. Muchas veces son "Lekitos", decorados con los mitos que relacionan la miel y la abeja con la vida y la muerte (Burn, L, 1985, 93).

Es dificil interpretar la causa de que los griegos, en sus funerales, colocaran estos recipientes de miel en la pira funeraria. Podría considerarse como una tradición simbólica que recordaba que, en un tiempo anterior a la incineración, embalsamaron sus cuerpos con miel antes de inhumarles ${ }^{65}$.

El valor sacrificial de la miel concuerda con la naturaleza ctónica de la abeja.

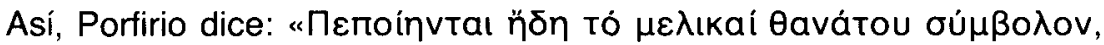

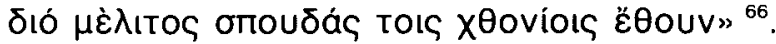

61 VARRON, Ap. NO Mac., 23-26.

${ }^{62}$ Hygin, Fab, 136; APOLL., Bibl., 111, 31.

${ }^{63} \mathrm{Hom}$. lLIADA, XIII, 170. A veces se utilizaba la cera en lugar de la miel: Herodoto, I, 140 y IV, 71; Cicer., Tusc., I, 45; Estrabon, XV, 735; Corn. Nep., Agesil., 7; Plutarco, Ages., 40.

${ }^{64}$ Xenoph., Hellen., V, 3, 19; Diod., XV, 93; F. Josph, Ant. Iud., XIV, 7-4; Stat. Silv. III, 2-11-8; Q. CURT., Alex, X, 101.

${ }^{65}$ HOMERO, lliada, XIII, 170 y Odisea, XXIV, 68.

${ }^{66}$ Porphir., De Ant. Nymph., 18. 


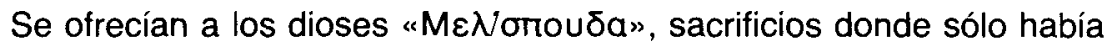
libaciones de miel. Plutarco las menciona como algo agradable a los dioses ${ }^{67}$.

Estas libaciones de miel generalmente eran ofrecidas a divinidades rústicas, protectoras de los agricultores: Pan, Flora, Priapo, las Ninfas y Hermes "Axpotńp" 68 .

Pero también se ofrecia la miel a divinidades de carácter ctónico: Artemis-Hécate, Deméter-Perséfone y Diónisos.

Estas divinidades no eran adversas al vino. Muchas veces la miel y el vino se ofrecian conjuntamente (las Bacantes de Eurípides derraman leche, vino y miel sobre la tierra). Pero otras veces, la miel sustituía al vino.

El ofrecer miel en lugar de vino puede tener como significación una supervivencia más antigua mantenida de un primitivo estado de la sociedad, cuando el vino no era aún conocido y donde la miel ocupaba un papel fundamental, incluso como bebida embriagante ${ }^{69}$.

Nonnos describe el paso por el cual la miel fue sustituida por el vino, bajo la forma de una contienda entre Aristeo y Diónisos, ganando este último ${ }^{70}$.

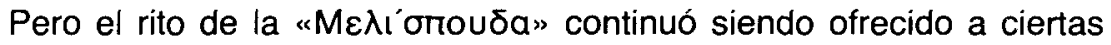
divinidades. Es más, en el templo de la Bona Dea, permaneció un cierto conservadurismo religioso y no se permitió el vino. Siempre fue la jarra de miel la ofrecida en libación ${ }^{71}$.

Finalmente, en la religiosidad antigua, la miel fue utilizada como medio de purificación y de limpieza grata a los dioses. Los iniciados en el mitraismo, en los misterios que simbolizaban la metamorfosis,

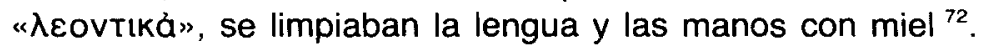

2.

${ }^{67}$ Plut., QV. Symp., IV, Varron, De Re Rust., III, 16 y XVI, 5; Pausanias, V, 15, 10, 6 ,

${ }^{68}$ Ovidio, Fast., III, 735; Calpur. Sic. Eccles., I, 66

${ }^{69}$ Plut., Qv. Symp. IV, 6, 672. B; Porphr., De ant. Nymph., 16. Cuenta como Cronos fue embriagado con una bebida hecha con miel por Zeus, en el mito órfico.

${ }^{70}$ Nonnos-Dion, XIII, 258-279 y XIX, 228-260.

7 En numerosos sacrificios ofrecidos a los dioses griegos se ofrece la miel con vino y con leche: Homero, Odisea, X, 518; Pausanias, V, XV, 6; Esquilo, Los Persas, 609; EuriPIDES, Orestes, 114-115; e Ifigenia, 162; SILIO ITALICO, XIII, 415.

${ }^{2}$ PORPhr. De Ant. Nymph., 15. 
Por todo ello, deduciríamos que la abeja y con ella su producto, la miel, fueron sagradas en tiempos prehistóricos. Más tarde, en una época histórica, se consideró a la abeja como un símbolo de rectitud y pureza en la vida terrena, $y$, tras la muerte, de resurrección y de inmortalidad, relacionándose con el culto de las divinidades ctónicas. Sería también símbolo de reencarnación del alma en las escuelas filosóficas del Neoplatonismo y el Orfismo. 


\section{BIBLIOGRAFIA}

BACHOFEN, J. J., 1987: El Matriarcado, Akal Universitaria, Madrid Bernabe, A., 1979: Textos Literarios Hetitas, Editora Nacional, Madrid. BLAZZUEZ, J. M., 1975: Diccionario de las Religiones Prerromanas de España, Istmo, Madrid

BurN, L., 1985: “Honey Pots: Tree White grounds cups by the Sotades painter", Antike Kunst, XXVIII, heft, 2, págs. 93 y ss.

Callender, M. H., 1965: Roman Amphorae, with index of Stamps, Londres.

Cook, A. B., 1895: "The bee in Greek Mythology", Journal of Hellenic Studies, págs. 1-24.

DEONNA, W.-RENARD, M., 1961: "Croyances et superstition de table dans la Rome Antique", Latomus, XLVI, págs. 19 y ss. Bruselas.

Detienne, E., 1963: Los jardines de Adonis, Akal Universitaria, Madrid.

Ebeling, E., 1938: “Biene», Reallexikon der Assyriologie, Columna 25, Berlin-Leipzig.

Flammenon, E., 1981: Dictionaire des Mythologies sous la direction de Ives Bonnefoy, T. 66 B., Paris.

GiL, L., 1979: Therapeia, Madrid.

GimBUTAS, M., 1974: The Gods and Goddesses of old Europe, 7000-3000 $B C$. Thames and Hudson, Londres.

GrimAL, P., 1966: Diccionario de la Mitología griega y romana, Labor, Barcelona.

HILL, G. T., 1966: Historical Greec Coins, Chicago.

HiMER, M., 1964: Die Griechische, Munich.

Lara Peinado, F., 1985: Mitos Sumerios y Acadios, Editora Nacional, Madrid. 
MONTET, P., 1983: La vida cotidiana en el Egipto de los Faraones, Argos Vergara, Barcelona.

Neumann, E., 1970: The Great Mother, Pricenton University Press.

ÖNEN, Ü., 1985: Epheusus, Esmirna.

Persson, A. W., 1941: "The Religion of Greec in Prehistoric Times", ISA, The Classical Lectures, XVII, págs. 9 y ss. Berkeley, Los Angeles.

SaLzmanN, A., 1890: "The Necropolis of Kamiros", Arch. Zeit., vol. XXXVII, págs. 111 y ss.

Sanz Mingote, L., 1988: "Anatolio e indoeuropeo. Estado de la cuestión". Estudios Clasicos, t. XXXI, n. ${ }^{\circ} 94$, págs. 65-81.

VON SODEN, W., 1987: Introducción al orientalismo antiguo. Aussa. Sabadell, Barcelona. 